\title{
Micro Hardness and Erosive Wear Behavior of Tungsten Carbide Filled Epoxy Polymer Nano Composites
}

\author{
M. Kameswara Reddy \\ Department of Mechanical Engineering, \\ National Institute of Technology Warangal, Telangana, India. \\ Corresponding author: mkreddynitw@gmail.com \\ V. Suresh Babu \\ Department of Mechanical Engineering, \\ National Institute of Technology Warangal, Telangana, India. \\ K. V. Sai Srinadh \\ Department of Mechanical Engineering, \\ National Institute of Technology Warangal, Telangana, India.
}

(Received September 4, 2019; Accepted February 19, 2020)

\begin{abstract}
The present work studies the tribological performance of Tungsten Carbide (WC) nanoparticles reinforced epoxy polymer nanocomposites. Polymer nanocomposites are prepared by hand lay-up method. Erosive wear and hardness tests were conducted to examine the physical and wear properties of epoxy/WC nanocomposites. Addition of WC nanoparticles led to significant reduction in erosion rate. In addition to that, incorporation of WC nanoparticles enhanced the hardness of epoxy nano composites. At $2 \%$ weight of WC nano filler, nanocomposites showed better performance in erosion wear properties and also in hardness. While at $3 \mathrm{wt} \%$ of WC filler, least performance in hardness was caused by the weak adhesive bonding between the matrix and filler. The nature of erosion wear behavior was observed. Finally worn surfaces of nanocomposites were inspected using a "scanning electron microscope (SEM)".
\end{abstract}

Keywords- Epoxy, Polymer nanocomposites, Tungsten carbide, Sand erosion, Hardness.

\section{Introduction}

Solid particle erosion is one of the wear types of a complex nature, in which erosion occurs by a combination of surface degradation and continuous loss of target substance due to continual impact of solid particles (Finnie, 1995). This type of erosion can cause loss of shine and transparency, increase in surface roughness and also pre-mature failure of structures and engineering components. Erosion leads to unnecessary costs and allied shutdowns in many industries. The surfaces of high speed moving objects like windmill blades, vehicles, surfing boats, aircrafts, etc. always undergo solid particle erosion due to solid particles present in the environment. In addition, steam turbine blades and inner surfaces of pipes in oil and gas production industries may erode due to the impingement of particles present in the slurry. Hence, Solid particle erosion is of main concern for these types of applications and materials with low erosion rate are essential.

For the past two decades, polymer utilization in a wide variety of industrial applications has increased significantly where body parts are exposed to fast moving solid particles (Fried, 2010). Polymer coating is regularly used as a foregoing layer to take care of body components from erosion, corrosion and abrasion (Fried, 2010). However, when compared to metals, the erosion 
International Journal of Mathematical, Engineering and Management Sciences

Vol. 5, No. 3, 405-415, 2020

https://doi.org/10.33889/IJMEMS.2020.5.3.034

wear resistance of polymers is two to three times lower in scale (Miyazaki, 2015). This can be overcome by the addition of small particles, platelets, carbon nanotubes, chopped fibers and hollow spheres in the polymers.

Zhou et al. (2013) prepared two types of nano silica (Pyrogenic and colloidal) reinforced polyacrylate based nano coating composites and observed the influence of key parameters such as nano silica content, erodent type, nano silica content and impact angle on the erosion behavior of composites. From their results, with sharp edge erodent type, the erosion resistance increased with filler volume. Based on the worn surface, they explained the failure phenomena. Chen et al. (2014) observed erosion wear performance of carbon nanotube (CNT) film composites, which had two different orientations (uni-directional- $0^{0}$, bi-directional $-0^{0} / 90^{\circ}$ ). Results show that unidirectional composite exhibits better erosion wear resistance than bi-directional composite. SEM analysis of worn surface provides better understanding of wear mechanism. Yousri et al. (2018) studied the effect of $\mathrm{Al}_{2} \mathrm{O}_{3}$ nanoparticles on mechanical, tribological and physical characterization of epoxy polymer by reinforcing alumina particles into it. Results reveal that, compared to neat epoxy there is an improvement in the hardness, mechanical strength and erosion wear resistance. Zhang et al. (2016) investigated the performance of graded SiC particles incorporated epoxy resin. From the results they observed that the graded $\mathrm{SiC}$ enhanced the hard spots and density, which intern leads to enhancement of erosion resistance.

The key factors that influence erosion wear of a filled polymer composites are: filler or fiber type (Harsha and Jha, 2008; Qian et al., 2010; Arani et al., 2019), filler content (Suresh et al., 2009; Yousri et al., 2018), orientation of fibre (Tewari et al., 2002; Kim and Kim, 2009; Drensky et al., 2011), filler and matrix interface (Arani et al., 2019), fiber volume and composition of a polymer (Lins et al., 2007; Arjula et al., 2008). On the other hand, testing conditions also influence the erosion wear behavior, which includes impingement velocity of a particle (Roy et al., 1994; Drensky et al., 2011; Arani et al., 2019), angle of impact of particle (Rajesh et al., 2001; Qian et al., 2010; Sinmazcelik and Sari, 2010; Arani et al., 2019), erodent type (Drensky et al., 2011), mass flow of erodent (Zahavi and Schmitt Jr, 1981; Tewari et al., 2002), erodent size (Sinmazcelik and Sari, 2010) and test temperature (Friedrich, 1986; Drensky et al., 2011). In the literature, only some studies have concentrated on the particle filled polymer composites, particularly for nanoparticle reinforced polymers, and many works have been on the fiber reinforced polymer composites.

The current research work deals with the preparation of tungsten carbide nanoparticles incorporated epoxy polymer, and analyzing the Erosion wear behavior of these composites at different test conditions such as particle impingement angles and particle impingement velocities. Finally worn surfaces were examined using SEM; also erosion wear mechanisms were discussed.

\section{Experimental Details \\ 2.1 Materials}

Epoxy (LY556), which can be cured at room temperature, was used as resin. This resin belongs to the family of diglycidyl ether of bisphenol A (DGEBA). Along with resin, an amino group family based hardener (HY951) was used as matrix. These two materials were supplied by SISCO Research Laboratories Pvt., Ltd., Hyderabad, India. At room temperature the density of epoxy and hardener are $1.15 \mathrm{~g} / \mathrm{cc}$ and $0.97 \mathrm{~g} / \mathrm{cc}$ respectively. Tungsten Carbide (WC) nano particles were used as filler reinforcements, which have a density of $15.63 \mathrm{~g} / \mathrm{cc}$ and of particle size $55 \mathrm{~nm}$. Nano particles are supplied by US Research Nanomaterials, Inc., Houston, USA. 
International Journal of Mathematical, Engineering and Management Sciences

Vol. 5, No. 3, 405-415, 2020

https://doi.org/10.33889/IJMEMS.2020.5.3.034

\subsection{Composites Fabrication}

Tungsten Carbide (WC) nano particles of known amount of weight were mixed into epoxy resin using mechanical stirrer for 20 minutes for getting uniform dispersion. Then, the required amount of hardener (epoxy to hardener by weight 100:12) according to stoichiometry was mixed into the resin and particle mixture, and mixed thoroughly for 10 minutes using mechanical stirrer at speed of 200rpm. A wooden mould of size $100 \mathrm{mmX} 100 \mathrm{mmX} 4 \mathrm{~mm}$ was prepared. Releasing agent was sprayed on the wooden mould surface, so that samples could be removed easily from the wooden mould. After that matrix with nano particles was poured into the wooden mould and kept at room temperature (RT) for 48 hours. Then the composites were taken out of the mould. Finally the required samples of size of $20 \mathrm{mmX} 20 \mathrm{mmX} 4 \mathrm{~mm}$ were cut by using diamond cutter which are shown in Figure 1. Samples that are prepared for different filler loading are given in Table 1.

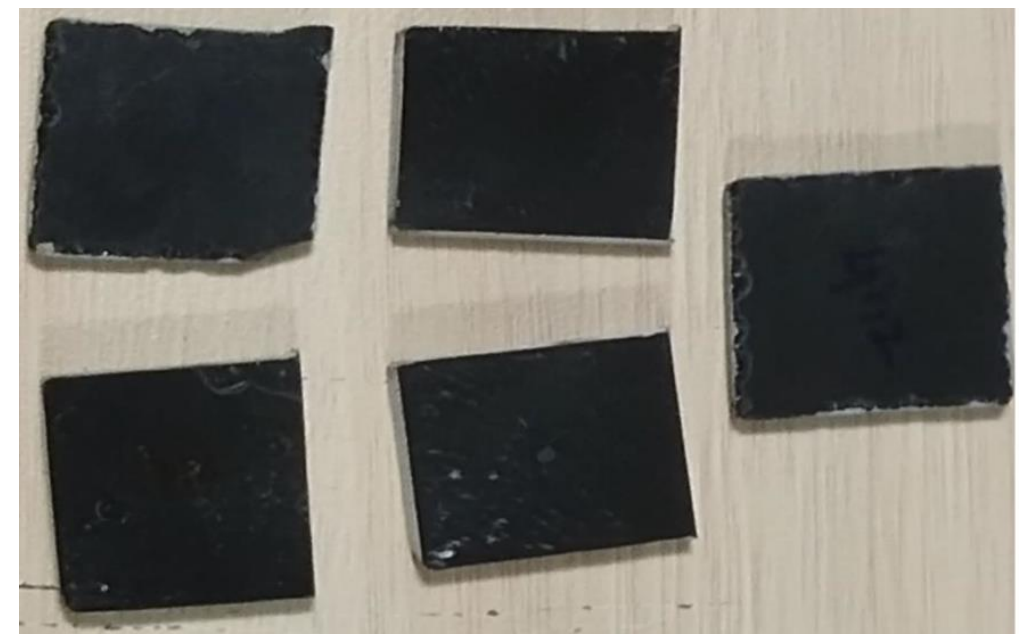

Figure 1. Nanocomposite samples prepared for erosion test

Table 1. Different types of composite samples prepared

\begin{tabular}{|c|c|c|}
\hline Sample Code & Matrix (epoxy + hardener) & $\begin{array}{c}\text { Filler(WC) } \\
\text { Wt.\% }\end{array}$ \\
\hline W0 & Wt. \% & 0 \\
\hline W1 & 100 & 1 \\
\hline W2 & 99 & 2 \\
\hline W3 & 98 & 3 \\
\hline W4 & 97 & 4 \\
\hline
\end{tabular}

\subsection{Nanocomposites Characterization}

\subsubsection{Hardness Test}

Vickers hardness test method was used to measure micro-hardness of the epoxy/WC nano composites. By the penetration of right pyramid form of diamond indenter, hardness value was measured for the sample. Vickers hardness value is measured by using the following relation:

$$
\text { Vickers hardness number }(H V) \approx \frac{1.854 P}{d^{2}}\left(\frac{\mathrm{kg}}{\mathrm{mm}^{2}}\right)
$$

where $\mathrm{P}$ is load applied in $\mathrm{kgf}$ and $\mathrm{d}$ is the mean of two diagonals of indentation in $\mathrm{mm}$. 
International Journal of Mathematical, Engineering and Management Sciences

Vol. 5, No. 3, 405-415, 2020

https://doi.org/10.33889/IJMEMS.2020.5.3.034

\subsubsection{Erosion Test}

Solid particle erosive wear test experiments on Epoxy nano composites were conducted as per standard ASTM G76 method on the erosion test rig. This erosion test rig is drawn schematically in Figure 2.The equipment consists of a compressor for accelerating sand particles by supplying compressed air into flow stream of sand particles, a conveyor belt for feeding particles and also controls sand particle flow moment, a mixing chamber for mixing sand particle and air, an adjustable sample holder and a swivel head for adjusting the angle of impact of sand particles on specimen and for maintaining the specimen at nozzle distance. Erosion test process parameters for the present work are shown in Table 2. An electronic weighing balance was used to determine the weight of the sample before erosion and after erosion. The accuracy of the weighing balance was $+/-0.01 \mathrm{mg}$. Eroded samples before weighing were cleaned with a flash of compressed air, so that any loosely adhering debris will be removed. The erosion rate of samples was measured in terms of the weight of composite specimen removed per unit weight of the erodent impacted during the experiment.

$$
\text { The rate of erosion wear is expressed in terms of } \frac{\Delta w_{1}}{\Delta w_{2}}
$$

where $\Delta w_{1}$ represents composite weight loss and $\Delta w_{2}$ represents erodent weight used for testing a sample.

Table 2. Testing conditions for erosion test

\begin{tabular}{|l|c|}
\hline Test parameters & Parameter value \\
\hline Erodent & Silica Sand \\
\hline Erodent size & $200+/-50$ \\
\hline Shape of erodent & Angular \\
\hline Hardness of particles & $30,45,60$ and 90 \\
\hline Angle of impact of particles(in deg) & 86 and 101 \\
\hline Velocity of impact of solid particles(m/s) & 2 \\
\hline Feed rate of erodent(gm/min) & RT \\
\hline Testing temperature & 10 \\
\hline Sample to Nozzle distance $(\mathrm{mm})$ & \\
\hline
\end{tabular}


International Journal of Mathematical, Engineering and Management Sciences

Vol. 5, No. 3, 405-415, 2020

https://doi.org/10.33889/IJMEMS.2020.5.3.034

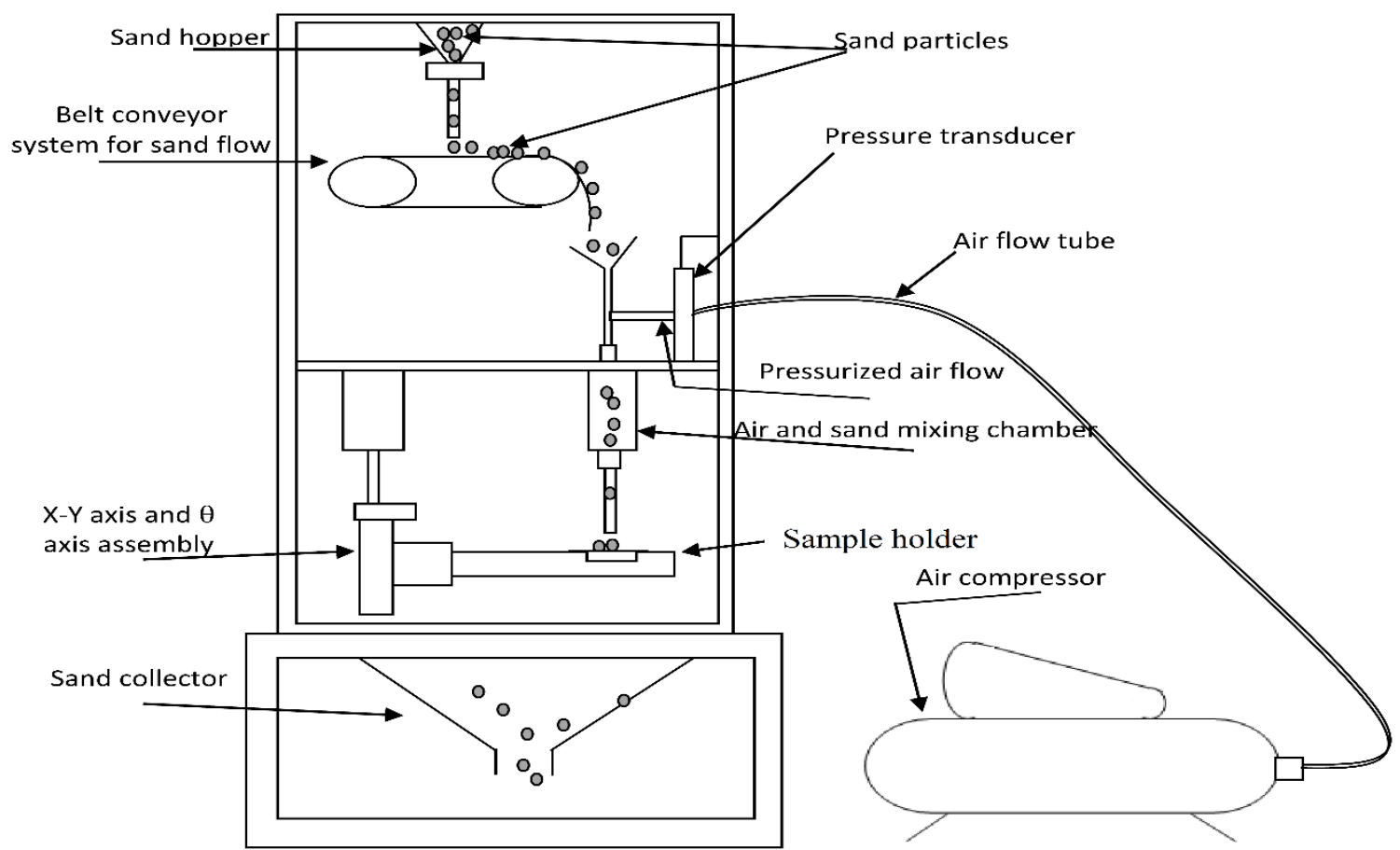

Figure 2. Schematic representation of solid particle erosion experimental setup

\subsubsection{Scanning Electron Microscopy}

Worn surface morphology of selected nanocomposites was observed by using a "scanning electron microscope (SEM)". Before microscopic examination the worn surfaces of the samples were coated with gold Particles.

\section{Results and Discussion}

\subsection{Hardness of Epoxy/WC Nanocomposites}

In the current section, Hardness of WC nanoparticles filled epoxy matrix nanocomposites have been discussed. A load of 10kgf was used to conduct Vickers Hardness test on the samples. With the variation of filler content in the epoxy, the variation of hardness is shown in Figure 3. It was observed that incorporation of $2 \mathrm{wt} \% \mathrm{WC}$ nanofiller achieved higher hardness, while at $3 \mathrm{wt} \%$ and $4 \mathrm{wt} \% \mathrm{WC}$ filler there is reduction of hardness. By the addition of particles from $1 \mathrm{wt} \% \mathrm{WC}$ to $2 \mathrm{wt} \% \mathrm{WC}$ trend shows increase in hardness, this corresponds to uniform dispersion of nanofiller. While at $3 \mathrm{wt} \%$ and $4 \mathrm{wt} \%$ of WC particles the phenomenon in reduction of hardness is due to the weak adhesion between WC nanofillers and epoxy matrix and also agglomeration of particles due to the increase of particles weight percentage. 
International Journal of Mathematical, Engineering and Management Sciences

Vol. 5, No. 3, 405-415, 2020

https://doi.org/10.33889/IJMEMS.2020.5.3.034

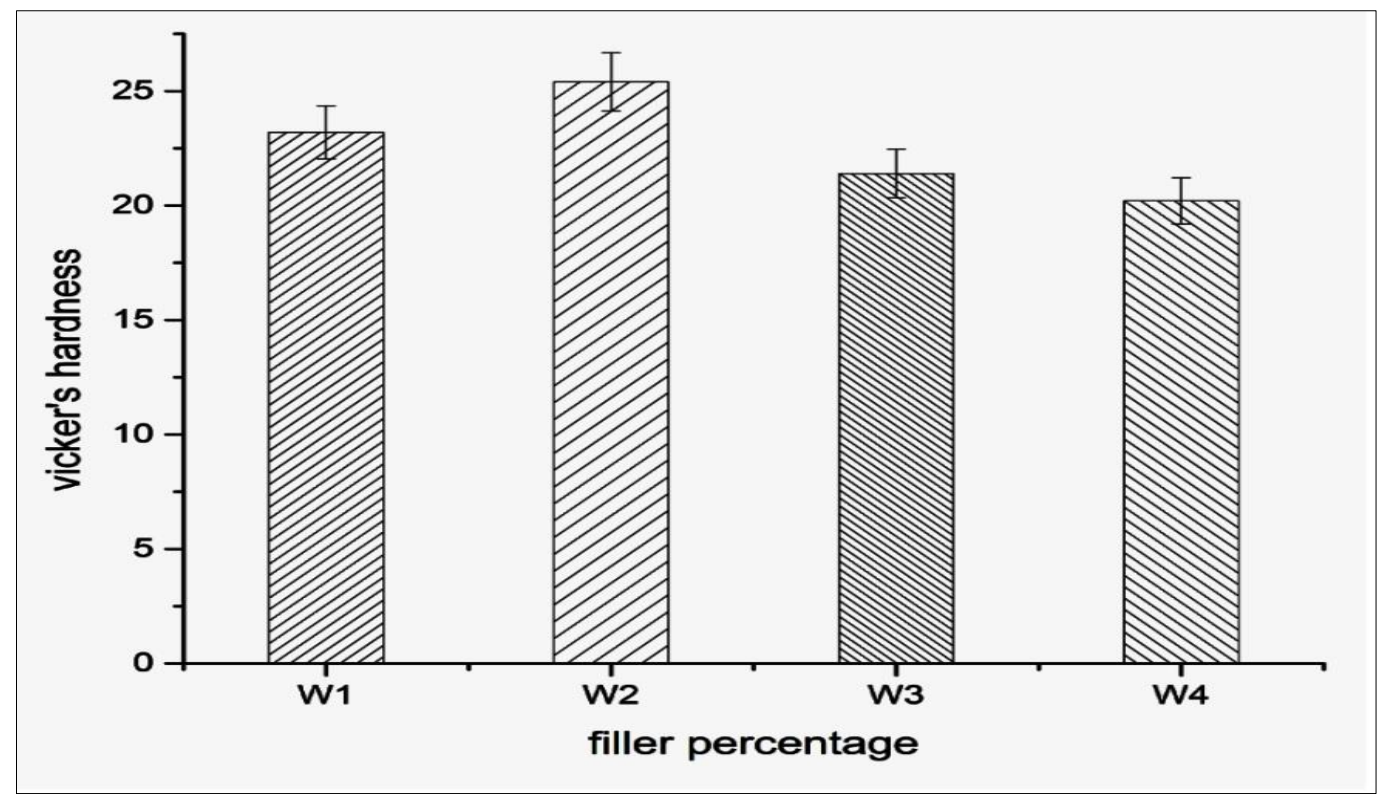

Figure 3. Hardness of Epoxy nanocomposites with addition of different wt $\%$ of WC nanoparticles

\subsection{Sand Erosion Wear Test}

In this section, tribological characterization of nanocomposites has been reported. The influence of nanoparaticles, which change the erosive wear properties of epoxy, has been studied. Nowadays when compared to the other conventional coatings, nanofiller reinforced polymer composite coatings are found to have uniform protection of coating surfaces for abrasive resistance and enhanced wear properties (Sawyer et al., 2003; Karger-Kocsis and Wu, 2004).

For studying the effect of filler weight percentage on erosive wear of nanocomposite, the composite specimens of varying filler weight percentage were subjected to erosion test for different impact angles and at a constant impact velocity of $86 \mathrm{~m} / \mathrm{s}$. Figure 4 plots the change in the rate of erosion of epoxy resin reinforced with a range of weight fractions of WC for definite impact angles ranging from $30^{\circ}$ to $90^{\circ}$. Except For neat epoxy of all other nanocomposites, the rate of erosion at impact angles $\left(45^{\circ}\right.$ and $\left.60^{\circ}\right)$ were in excess of those at impact angles $\left(30^{\circ}\right.$ and $90^{\circ}$ ) and the utmost erosion rate was at an impact angle of $45^{\circ}$. However, for neat epoxy, erosion rate is maximum at $30^{\circ}$ impact angle. In general, based on previous research, for any material, if the maximum rate of erosion occurs at low impact angles (i.e. $15^{0}-30^{\circ}$ ) then the erosion failure mode of a material is ductile in nature, On the contrary, if maximum rate of erosion occurs at higher impact angles (i.e. $70^{\circ}-90^{\circ}$ ) then the erosion failure mode of a material is brittle in nature (Arnold and Hutchings, 1992; Arnold and Hutchings, 1993; Zhou et al., 2013; Chen et al., 2014). From the results, Irrespective of filler weight percentage maximum erosion rate for all the specimens was observed at an impact angle of $45^{\circ}$. So, erosive wear behavior for these composites is semi ductile in nature, but for neat epoxy the behavior is ductile in nature. The change in nature from ductile to semi-ductile by the addition of particles is due to the brittle nature of tungsten carbide particles. This type of change in erosion wear behavior by the addition of carbon fiber to the neat epoxy was observed by Chen et al. (2014). From the test it was evident 
International Journal of Mathematical, Engineering and Management Sciences

Vol. 5, No. 3, 405-415, 2020

https://doi.org/10.33889/IJMEMS.2020.5.3.034

that the erosion resistance can be enhanced with the addition of WC nano filler into the epoxy resin which is in Figure 4. It was still observed that $2 \mathrm{wt} \%$ filled epoxy resin samples showed maximum erosion resistance compared to $1 \mathrm{wt} \%$ and $3 \mathrm{wt} \% \mathrm{WC}$ filled epoxy nanocomposites. Higher erosion rate at $3 \mathrm{wt} \%$ of filler is due to reduction in hardness.

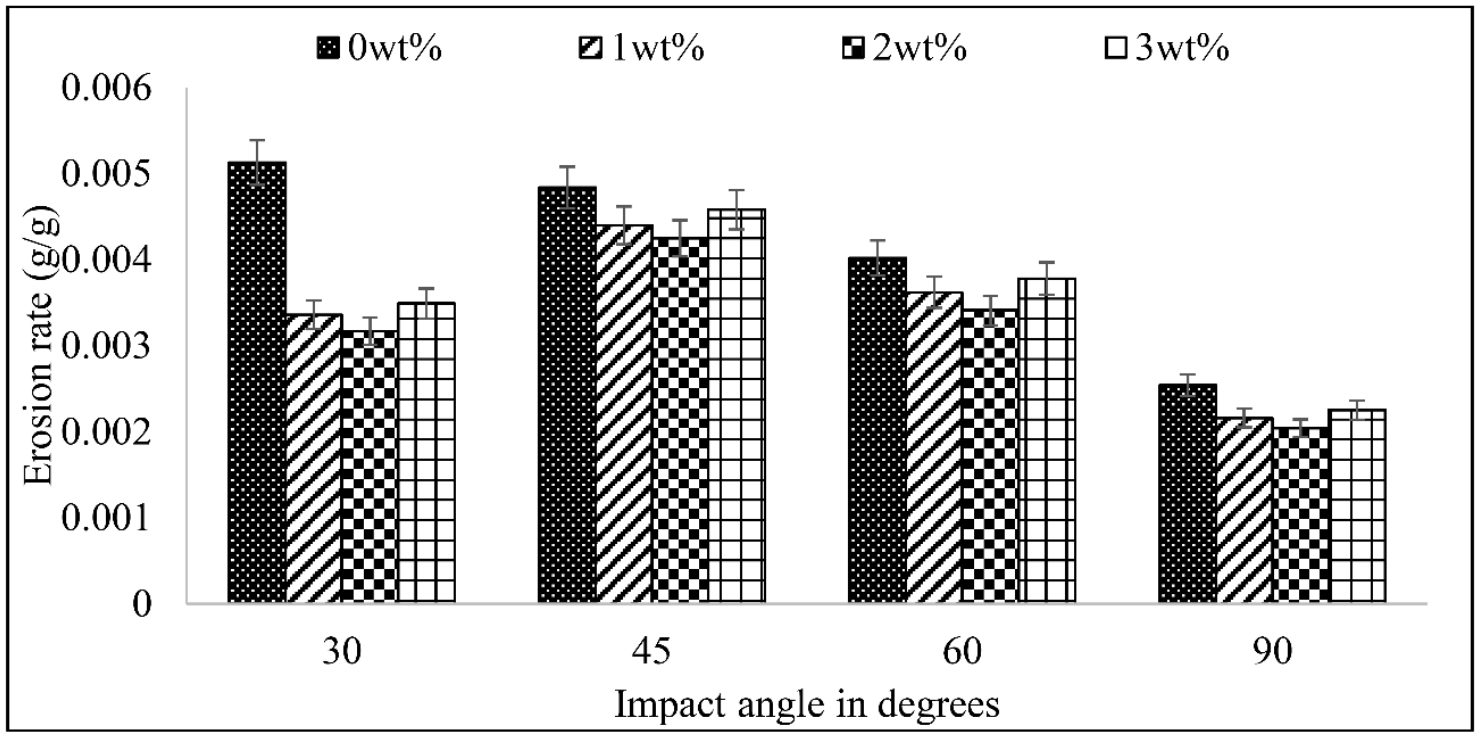

Figure 4. Erosion rate of epoxy resin filled with various WC weight fractions, for different impact angles and at an impact velocity of $86 \mathrm{~m} / \mathrm{s}$

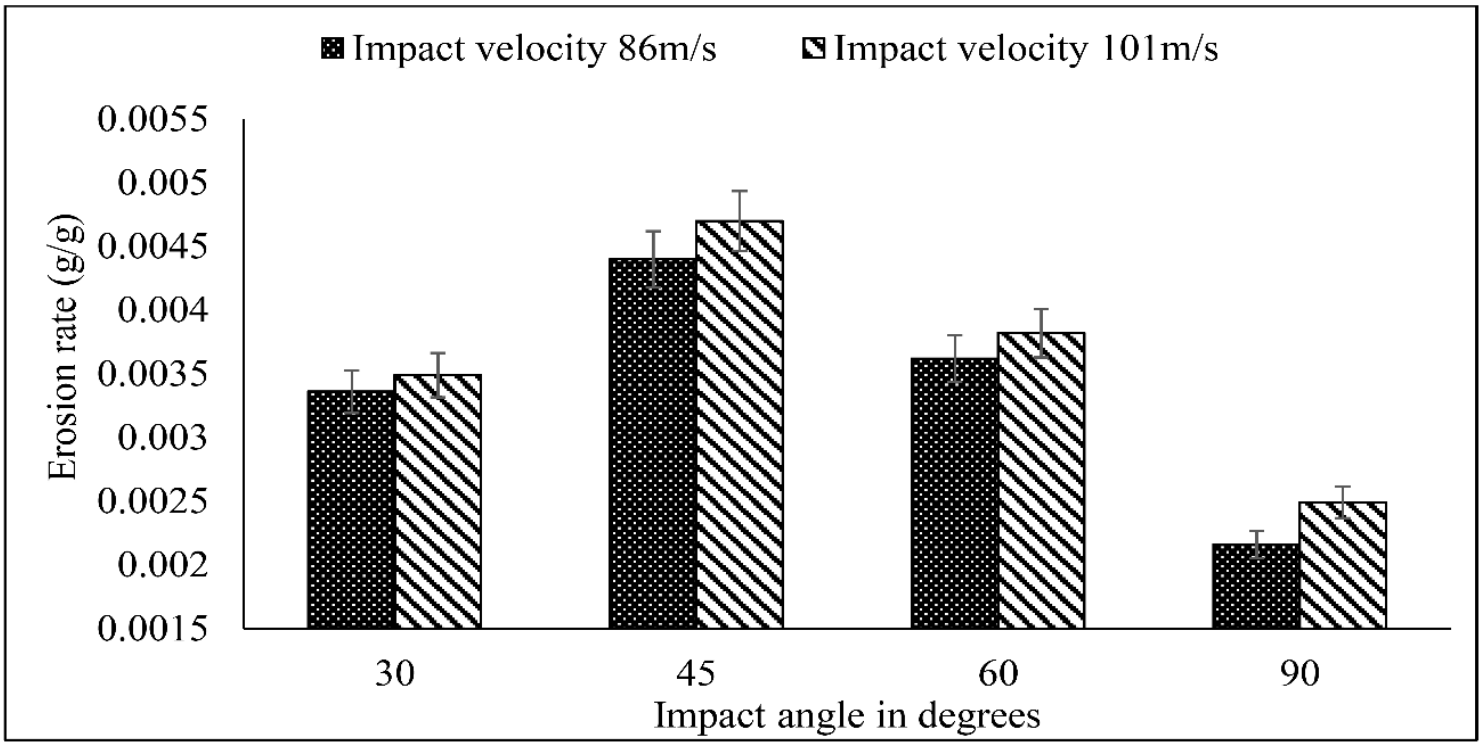

Figure 5. Erosion rate for $1 \mathrm{wt} \%$ of filler nanocomposites at an impact velocity of $86 \mathrm{~m} / \mathrm{s}$ and $101 \mathrm{~m} / \mathrm{s}$ 
International Journal of Mathematical, Engineering and Management Sciences

Vol. 5, No. 3, 405-415, 2020

https://doi.org/10.33889/IJMEMS.2020.5.3.034

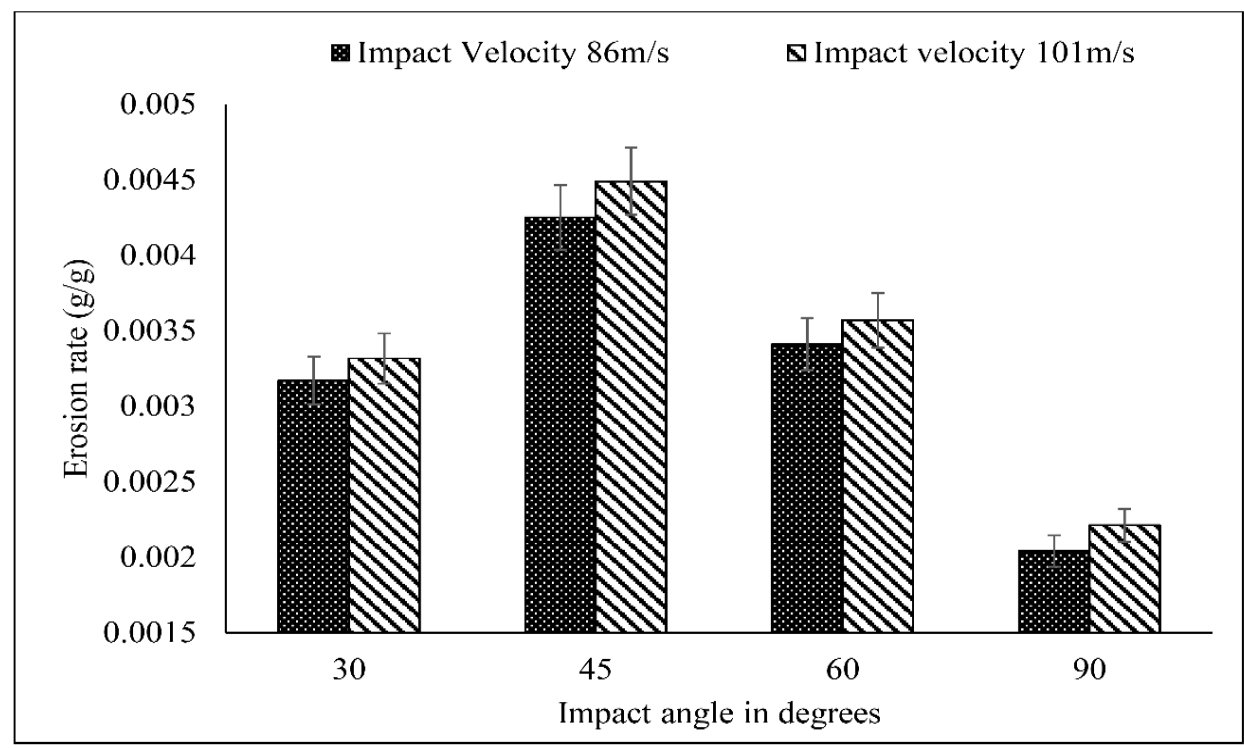

Figure 6. Erosion rate for $2 \mathrm{wt} \%$ of filler nanocomposites at an impact velocity of $86 \mathrm{~m} / \mathrm{s}$ and $101 \mathrm{~m} / \mathrm{s}$

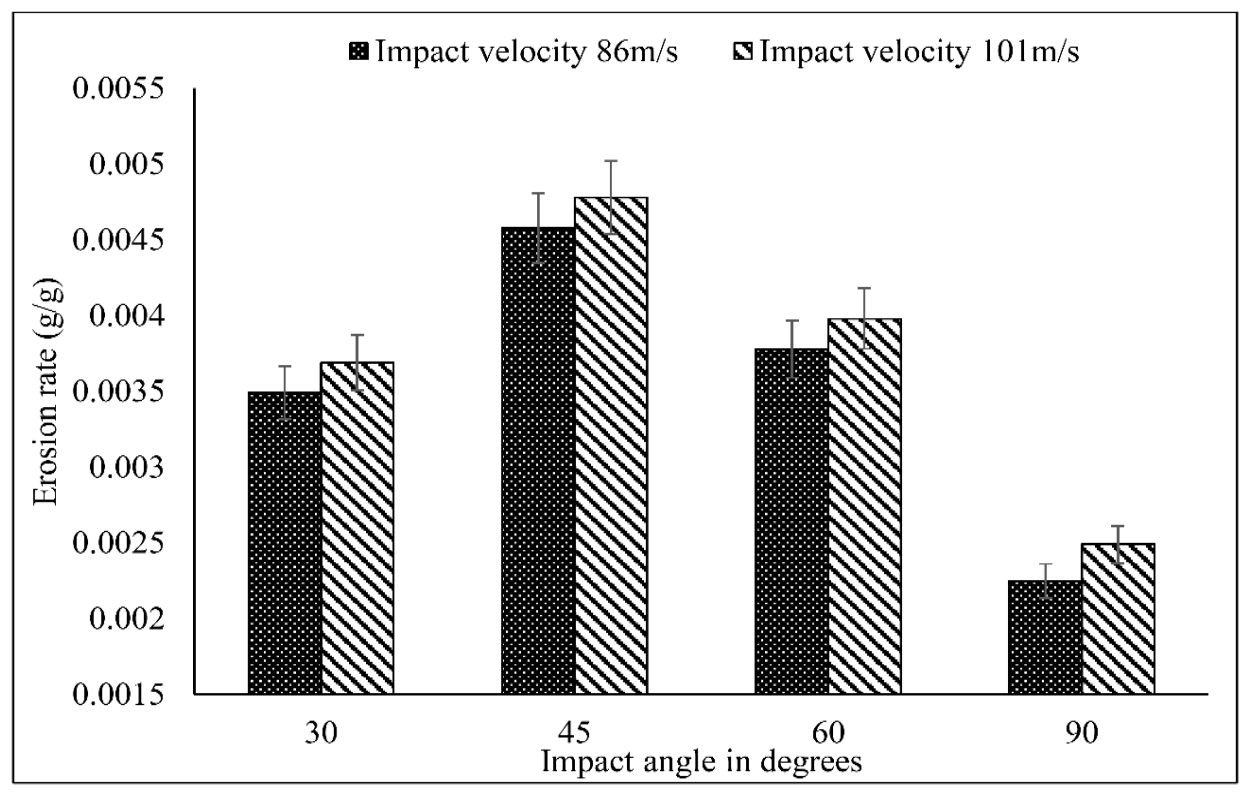

Figure 7. Erosion rate for $3 \mathrm{wt} \%$ of filler nanocomposites at an impact velocity of $86 \mathrm{~m} / \mathrm{s}$ and $101 \mathrm{~m} / \mathrm{s}$

Material removal at high impact speed of solid particles present in the surrounding environment of equipment is one of the major causes of failure occurring in materials. Figure 5, Figure 6 and Figure 7 represents the loss of material due to erosion of composites, incorporated with various WC contents for two levels of impact velocity. Erosive particle impact velocity has a strong significance on wear process. From the results it was concluded that erosive rate was high at higher impact velocity caused by high kinetic energy of the impending particles (Syamsundar et 
International Journal of Mathematical, Engineering and Management Sciences

Vol. 5, No. 3, 405-415, 2020

https://doi.org/10.33889/IJMEMS.2020.5.3.034

al., 2015). Same type phenomena i.e. increase of erosion rate with increase of velocity was observed by Panchal et al. (2018). However, Irrespective of the particles impact velocity, erosion behavior of composites at various weight percentages of Tungsten carbide particles is the same.

\subsection{Microstructure}

Eroded surface was observed using SEM. In general, Basic erosion wear, a mechanism of polymer composites, is as follows: there is micro crack on matrix surface to start with, followed by de-bonding of matrix and finally removal of material. SEM image in Figure 8 shows how the impact of solid particles on composite causes matrix breakage micro cracks on the composite. Crater and Flake type Debris of matrix on the sample surface was also observed. Zhou et al. (2013) also observed similar type of worn mechanisms.
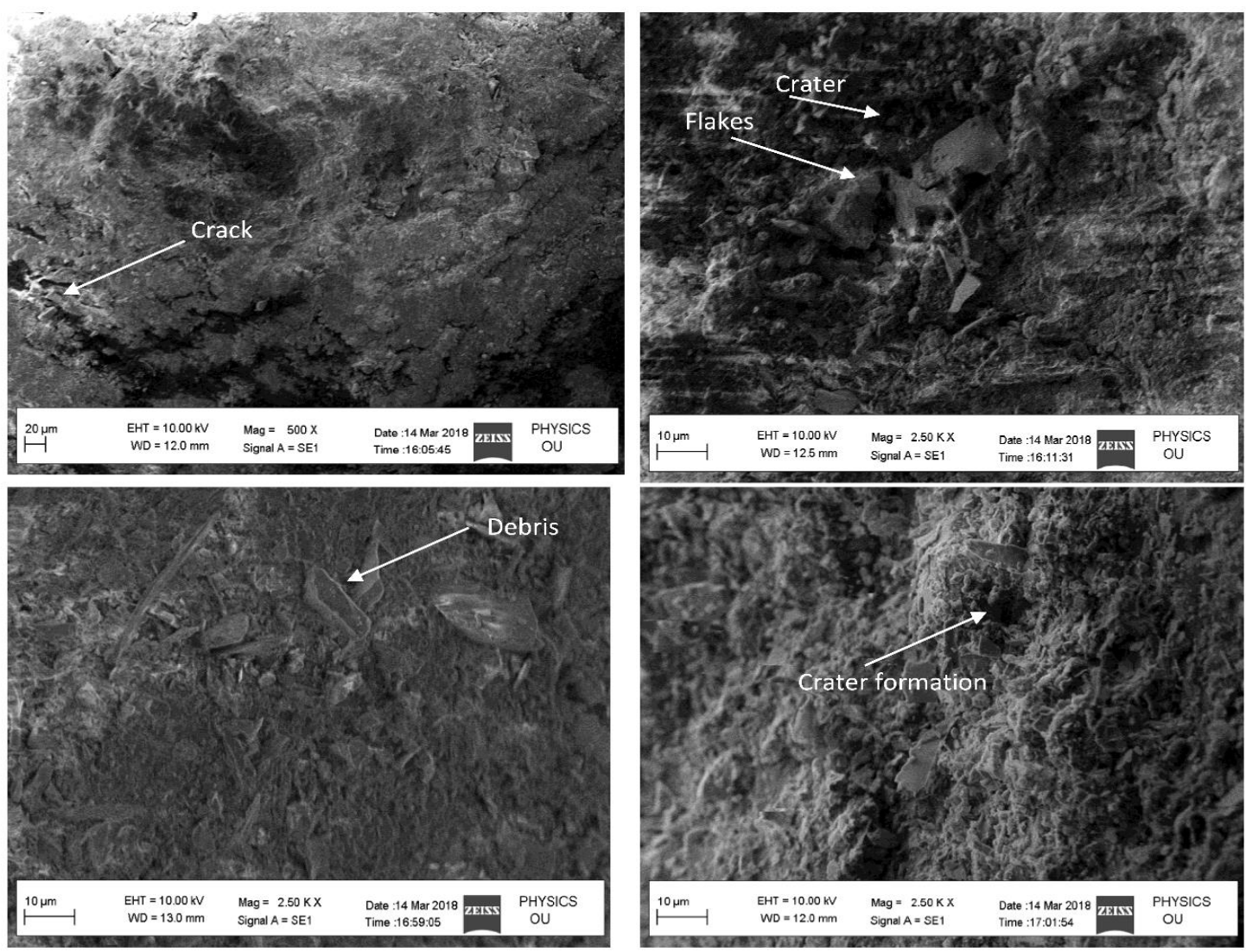

Figure 8. SEM images of worn surfaces at particle impact angle of $60^{\circ}$ and at particle impact velocity of $86 \mathrm{~m} / \mathrm{s}$

\section{Conclusions}

Tests were carried out to establish the result of WC nanoparticles on the erosion resistance of epoxy nanocomposites using silica sand as an erodent. From the experimental results, the following conclusions are drawn. 
International Journal of Mathematical, Engineering and Management Sciences

Vol. 5, No. 3, 405-415, 2020

https://doi.org/10.33889/IJMEMS.2020.5.3.034

- The erosion resistance of neat epoxy resin can be enhanced by adding WC filler at all angles of impact of solid particles.

- Epoxy/WC nano-composite with $2 \mathrm{wt} \%$ of filler exhibited higher erosion wear resistance and hardness than those compared to $1 \mathrm{wt} \%$ and $3 \mathrm{wt} \%$.

- All the composites exhibited semi-ductile form of erosion, with highest erosion rate at $45^{\circ}$ angle.

- The change in nature of epoxy composites from ductile to semi-ductile nature by the addition of particles is due to the brittle nature of tungsten carbide particles.

- The erosion rates of WC filled epoxy resin increases with increase in impingement velocity of erodent.

\section{Conflict of Interest}

The authors confirm that there is no conflict of interest to publish the paper in the journal.

\section{Acknowledgment}

Authors would like to acknowledge and thank the National Institute of technology Warangal, Telangana, India-506004, which supported us to carry out the research work by providing laboratory. The authors sincerely appreciate the editor and reviewers for their time and valuable comments.

\section{References}

Arani, N.H., Rabba, W., \& Papini, M. (2019). Solid particle erosion of epoxy matrix composites reinforced by $\mathrm{Al}_{2} \mathrm{O}_{3}$ Spheres. Tribology International, 136, 432-445.

Arjula, S., Harsha, A.P., \& Ghosh, M.K. (2008). Solid-particle erosion behavior of high-performance thermoplastic polymers. Journal of Materials Science, 43(6), 1757-1768.

Arnold, J.C., \& Hutchings, I.M. (1992). Model for the erosive wear of rubber at oblique impact angles. Journal of Physics D: Applied Physics, 25(1A), A222-A229.

Arnold, J.C., \& Hutchings, I.M. (1993). Erosive wear of rubber by solid particles at normal incidence. Wear, 161(1-2), 213-221.

Chen, J., Trevarthen, J.A., Deng, T., Bradley, M.S.A., Rahatekar, S.S., \& Koziol, K.K.K. (2014). Aligned carbon nanotube reinforced high performance polymer composites with low erosive wear. Composites Part A: Applied Science and Manufacturing, 67, 86-95.

Drensky, G., Hamed, A., Tabakoff, W., \& Abot, J. (2011). Experimental investigation of polymer matrix reinforced composite erosion characteristics. Wear, 270(3-4), 146-151.

Finnie, I. (1995). Some reflections on the past and future of erosion. Wear, 186-187, 1-10.

Fried, J.R. (2010). Polymers in aerospace applications. Smithers Rapra Technology, United Kingdom.

Friedrich, K. (1986). Erosive wear of polymer surfaces by steel ball blasting. Journal of Materials Science, 21(9), 3317-3332.

Harsha, A.P., \& Jha, S.K. (2008). Erosive wear studies of epoxy-based composites at normal incidence. Wear, 265(7-8), 1129-1135. 
International Journal of Mathematical, Engineering and Management Sciences

Vol. 5, No. 3, 405-415, 2020

https://doi.org/10.33889/IJMEMS.2020.5.3.034

Karger-Kocsis, J., \& Wu, C.-M. (2004). Thermoset rubber/layered silicate nanocomposites. Status and future trends. Polymer Engineering and Science, 44(6), 1083-1093.

Kim, A., \& Kim, I. (2009). Solid particle erosion of CFRP composite with different laminate orientations. Wear, 267(11), 1922-1926.

Lins, V.F.C., Branco, J.R.T., Diniz, F.R.C., Brogan, J.C., \& Berndt, C.C. (2007). Erosion behavior of thermal sprayed, recycled polymer and ethylene-methacrylic acid composite coatings. Wear, 262(3-4), $274-281$.

Miyazaki, N. (2015). Solid particle erosion of composite materials: a critical review. Journal of Composite Materials, 50(23), 3175-3217.

Panchal, M., Raghavendra, G., Om Prakash, M., \& Ojha, S. (2018). Effects of environmental conditions on erosion wear of eggshell particulate epoxy composites. Silicon, 10(2), 627-634.

Qian, D., Bao, L., Takatera, M., Kemmochi, K., \& Yamanaka, A. (2010). Fiber-reinforced polymer composite materials with high specific strength and excellent solid particle erosion resistance. Wear, 268(3-4), 637-642.

Rajesh, J.J., Bijwe, J., Tewari, U.S., \& Venkataraman, B. (2001). Erosive wear behavior of various polyamides. Wear, 249(8), 702-714.

Roy, M., Vishwanathan, B., \& Sundararajan, G. (1994). The solid particle erosion of polymer matrix composites. Wear, 171(1-2), 149-161.

Sawyer, W.G., Freudenberg, K.D., Bhimaraj, P., \& Schadler, L.S. (2003). A study on the friction and wear behavior of PTFE filled with alumina nanoparticles. Wear, 254(5-6), 573-580.

Sinmazcelik, T., \& Sari, N.Y. (2010). Erodent size effect on the erosion of polyphenylene sulfide composite. Polymer Composites, 31(6), 985-994.

Suresh, A., Harsha, A.P., \& Ghosh, M.K. (2009). Solid particle erosion studies on polyphenylene sulfide composites and prediction on erosion data using artificial neural networks. Wear, 266(1-2), 184-193.

Syamsundar, C., Chatterjee, D., Kamaraj, M., \& Maiti, A.K. (2015). Erosion characteristics of nanoparticle-reinforced polyurethane coatings on stainless steel substrate. Journal of Materials Engineering and Performance, 24(4), 1391-1405.

Tewari, U.S., Harsha, A.P., H“ager, A.M., \& Friedrich, K. (2002). Solid particle erosion of unidirectional carbon fibre reinforced polyetheretherketone composites. Wear, 252(11-12), 992-1000.

Yousri, O.M., Abdellatif, M.H., \& Bassioni, G. (2018). Effect of $\mathrm{Al}_{2} \mathrm{O}_{3}$ nanoparticles on the mechanical and physical properties of epoxy composite. Arabian Journal of Science and Engineering, 43(3), 1511-1517.

Zahavi, J., \& Schmitt Jr, G.F. (1981). Solid particle erosion of polymeric coatings. Wear, 71(2), 191-210.

Zhang, Y., Zhang, H., Yang, J., \& Geng, G. (2016). Erosion resistance and interface properties of epoxy composite filled with graded silicon carbide. Polymers and Polymer Composites, 24(2), 161-166.

Zhou, L.Y., Zhang, H., Pei, X.Q., Friedrich, K., Eger, C., \& Zhang, Z. (2013). Erosive wear of transparent nanocomposite coatings. Tribology International, 61, 62-69. 